\title{
Changes of androgens levels in menopausal women
}

\author{
Maria Brzozowska, Andrzej Lewiński \\ Department of Endocrinology and Metabolic Diseases, Medical University, Lodz, Poland \\ Department of Endocrinology and Metabolic Diseases, Polish Mother's Memorial Hospital Research Institute, Lodz, Poland
}

\begin{abstract}
Androgens play an important role in women's health. They are responsible for the sexual well-being and for maintaining proper structure and function of genitourinary woman's tract. In menopausal period a relative increase in androgens level is observed as a result of dramatic demise of estrogens and increase of sex hormonebinding globulin (SHBG). However, the response of target tissue depends on its ability to control androgens availability. In menopausal women the symptoms of both hyperandrogenemia and of androgens deficiency may be observed. Hyperandrogenemia may result in discrete symptoms, such as slight terminal facial hair grow, or worsening of scalp hair loss. Those symptoms should not be belittled in any of the cases, especially when their severity increases one should seek possible causes of postmenopausal hyperandrogenemia.

Ovarian and adrenal aging, leading to a progressive decline in androgen levels, may exert detrimental effects on the quality of life. During menopause, changes in activation of particular brain spheres are connected with low sex hormone concentration and correlate with loss of sexual arousability. Hypoactive sexual desire dysfunction (HSDD) may be the direct result of androgens deficiency in menopausal women. It is the only evidence-based indication for the use of testosterone in women. However, before treatment, other diseases must be excluded that might alternatively be the cause of HSDD.
\end{abstract}

Key words: androgens, women physiology, hypoactive sexual desire dysfunction, menopause.

\section{Introduction}

Androgens play an important role in many aspects of women's health and their well-being [1]. Luteinizing hormone (LH) stimulation has an impact on androgen secretion in pre- and post-menopausal women. After menopause, increased gonadotropin levels maintain ovarian androgen secretion besides the substantial estrogen demise $[2,3]$. This imbalance between estrogens and androgens after menopause is strengthen by the evolving decrease in sex hormone-binding globulin (SHBG) concentrations and the subsequent increase in free androgen index (FAI) [4]. Ovarian and adrenal aging, leading to a progressive decline in androgen levels, may exert detrimental effects on the quality of life. Sexual function worsens with advancing menopause level. Declining levels of sex steroids play a major role in deterioration of sexual response [5]. What should be taken into consideration are psychological changes dependent on aging and an increase in metabolic and cardiovascular comorbidities in elderly. Furthermore, it should be recalled that human-specific and highly sophisticated mechanisms of intracrinology permit each cell to control androgen availability according to its own needs, independently from the remaining of the body, that may cause variable response to declining levels of androgens in women after menopause [6].

This review article is up to depict the physiological changes in androgens secretion and their impact on postmenopausal women.

\section{Androgens in physiology of women}

It is stated that the source of androgens in women - testosterone (T), dehydroepiandrosterone (DHEA), dehydroepiandrosterone sulphate (DHEAS), androstenedione (A4) and dihydrotestosterone (DHT) - are ovaries, adrenals and peripheral tissues (the skin). ACTH is in control of adrenal synthesis; though negative feedback regulation of ACTH secretion by androgens is not observed. Androgen secretion from ovaries is dependent on theca cells stimulation governed by LH. On the contrary to women, male androgens do not hamper $\mathrm{LH}$ secretion from the pituitary gland [1]. Androgens transported in blood occur mostly bound with SHBG or albumins, and as a result, those androgens do not show biological activity. Only DHEA and DHEAS exhibit little or no binding [7]. Approximately $0.5-7.5 \%$ of them arise in the free form (unbound), enabling their activity in tar- 
get tissues [8]. Enzymes present in peripheral tissues have the ability to transform DHEAS into DHEA, next - into A4 and T, and further - $T$ into the most active androgen - DHT (5-reductase is present in the skin). Other tissues and organs, like the liver, muscles, fat tissue, skin, kidneys or bones, retain enzymatic activity 17hydroxysteroid dehydrogenase, allowing $T$ conversion to estrone (E1), the latter exhibiting para- and interactive effects in tissues [9]. The skin is an important site for peripheral conversion of androgens; at least $50 \%$ of a woman's androgen production occurs here, as DHEAS is converted to DHEA, the latter hormone to A4, A4 into $\mathrm{T}$, and finally $\mathrm{T}$ to $\mathrm{DHT}[1]$.

Steroid hormones are important for maintaining proper structure and function of genitourinary woman's tract [10-14]. In healthy young women the vagina has a stratified squamous epithelium composed of 3 cell layers consisting of superficial and intermediate cells with few parabasal cells. Normal proliferation of the epithelium leads to the formation of moist and thick rugae on the mucosal surface of the vagina and glycogen released by exfoliated epithelial cells is hydrolyzed into glucose. Then, glucose is metabolized mainly by lactobacilli into lactic acid, creating an acidic environment that discourages the growth of pathogenic bacteria and fungi $[13,15]$. In postmenopausal women, $T$ and estrogens are synthesized locally in extragonadal tissues with circulating precursor androgens (DHEA and A4) $[16,17]$. They manage cells proliferation and maintain vaginal epithelium condition [18]. The highest secretion of androgens and their precursors is observed in women who are in age between 20 and 30 years; later, their concentration gradually decreases by $50 \%$, up to 40 years in T, DHEA and DHEAS spectrum $[19,20]$. In the next years of life, androgens secretion is diminished by $25 \%$ (up to 50 years) and the process continues after 60 years, though is less intense comparing to the age of 50 [21].

\section{Androgens in menopause}

It is said that in post-menopausal women ovaries remain hormonally active, producing androgens even up to 10 years after menstruation end [22, 23]. Estrogen concentration decreases in an abrupt and drastic way within postmenopausal period, whereas androgen concentration gradually decreases over the years. Ovary androgens secretion, before menopause and directly after it, is dependent on ovaries stimulation, which is governed by $\mathrm{LH}$, i.e. gonadotropin, the concentration of which at this period increases [23]. Additionally, decrease in concentration of SHBG in menopausal period is a consequence of the rapid slump in estrogen secretion and boosts the pool of available T, which is marked as FAI [22, 23]. Additionally, in women before and after menopause, especially those obese ones, androgen se- cretion can intensify conditions like insulin resistance and excessive insulin production which stimulates the ovaries to produce androgen [24].

What can be understood is that sudden estradiol (E2) concentration decrease, with resistant quantities of $\mathrm{T}$ and low SHBG concentration in post-menopausal women, in a natural manner directs the hormonal balance to hyperandrogenemia. It may result in discrete hyperandrogenemia symptoms, such as slight terminal facial hair grow, or worsening of scalp hair loss [25]. Those symptoms should not be belittled in any of the cases, especially when their severity increases one should seek possible causes of postmenopausal hyperandrogenemia $[25,26]$.

However, what is observed, is that androgen concentration in postmenopausal women may be significantly lower in comparison to women in their 20s/30s [10]. After menopause, structural and functional changes in genitourinary tract occur under the influence of decreased sex hormone production and lead to the situation that may be compared to pre-puberty period. Anatomic alterations in vulvar, clitoral, vestibular, urethral, vaginal, anterior vaginal wall, periurethral, and bladder tissues may be observed [10]. Vulvar tissue can appear diminished, obliterated, or even fused, and irritation or erythema can be evident [27]. The introitus becomes narrow with a loss of hymenal remnants, the cervix can become flush with the vaginal vault, and pelvic organ prolapse is not uncommon [27]. The vagina can become shortened and narrowed; its surface can appear thinner, less elastic, and smoother (fewer rugae) with visible petechiae from intradermal or submucosal bleeding or inflammation. Urethral changes can include development of a urethral caruncle with urethral prolapse when the mucosa is circumferentially everted at the meatus. The loss of acidity in the vagina is associated with decreased resistance to non-native bacterial or fungal infection and there could be subsequent development of ascending bladder infections, overactive bladder, or recurrent urinary tract infections [28].

Initial observations that vaginal atrophy was less prevalent in postmenopausal women with higher levels of A4 and T [29] left open the possibility that T could be converted to E2 by aromatase. However, in a study involving a small number of women with breast cancer undergoing aromatase inhibitor therapy, intravaginal (vaginal mucosa) application of T for 4 weeks was shown to ameliorate the signs and symptoms of vaginal atrophy (dyspareunia, vaginal dryness, vaginal $\mathrm{pH}$, and epithelial maturation) [30], suggesting that androgens could have an independent effect on epithelial growth.

It is claimed that sexual behavior, mood and emotional condition and cognition abilities are modulated by sex hormones throughout woman's life. During perimenopausal period, and especially after menopause, recession in sex hormone concentration may impact on 
woman's well being. During menopause, changes in activation of particular brain spheres are connected with low sex hormone concentration and correlate with loss of sexual arousability [5]. It is believed that independently of age, once menopause progresses the sexual functions deteriorate. The most common symptoms are low libido (40-50\%), vaginal dryness (25-30\%)s, and pain experienced while sexual intercourse (12-45\%), one of the complications of genitourinary syndrome of menopause (GSM) [31].

The Endocrine Society Guidelines [32] do not recommend the use of clinical diagnosis of "androgen deficiency syndrome" in healthy women, mainly because standardized and exact measuring methods checking $T$ level in blood are not available. Moreover, the concentration of circulating androgens does not reflect final individual exposition and peripheral tissues sensitivity.

The hypoactive sexual desire dysfunction (HSDD) is defined as stagnation in sexual desire, which is not connected with other medical conditions, physiology or conditions resulting in taking medicaments. It is observed that in women who are between 20 and 70 , HSDD occurred more often as a result of surgical menopause rather than of physiological menopause. It is suggested that predispositions or other physiological or socio-cultural factors may affect sexual dysfunctions during menopause $[33,34]$. It is stated that other diseases may co-exist with menopause time such as hyperprolactinemia [35], hypopituitarism, adrenal insufficiency, and chemical ovarian suppression during which the concentration of androgens is lowered. Other conditions as overt [36-38] or subclinical [36, 39] hypothyroidism and hyperthyroidism have been associated with reduced sexual desire in themselves. Low androgens level may be directly connected with impaired synthesis of sex hormones, or indirectly with increase of SHBG as in hyperthyroid patients. In depressive states the growth of sexual disorders is noticed (50\% to $70 \%$ in creased risk of sexual dysfunction, and the occurrence of sexual dysfunction is associated with a $130 \%$ to $210 \%$ increased risk of depression $[40,41]$; on the other hand, sexual disorders may intensify depressive states. Additionally, taking antidepressant medicaments may perturb sexual desire [42-45]. Other common pathology connected with menopause may be carbohydrate metabolism disorders in the state of pre-diabetes, insulin resistance or diabetes, which hamper sexual desire [46]. Reduced sexual desire and sexual satisfaction were strongly associated with insulin resistance and, therefore, susceptible to changes in insulin sensitivity [46]. Obesity and metabolic condition in that time may affect sexual dysfunctions. Data proved that the sexual desire is inversely associated with body mass index [4749]. Both obesity and metabolic syndrome have been associated with increased baseline clitoral vascular resistance and impaired sexual arousal, suggesting that the negative impact of these metabolic phenotypes on sexual function is primarily at the genital level rather than a central effect [50]. What is stated is that co-existence of other diseases in menopausal women may strengthen the effects of low androgen concentration, or alternatively be the cause of HSDD in this population [51]. It is thought that HSDD, in accordance with the Endocrine Society recommendations 2019, is the only indication to use $T$ in menopausal women. There is not sufficient data confirming the efficacy of such treatment for other indications. HSDD diagnosis must be deliberated, based on excluding other factors which may lead to sexual disorders in that women population [52].

\section{Conclusions}

After menopause, estrogens fall to undetectable levels. Consequently, the small amount of remaining T may predispose to androgenic symptoms, especially acne, increased facial hair growth and male pattern baldness [23]. Androgens contribute to libido, sexual arousal and orgasm by increasing dopamine levels in the central nervous system. Testosterone also maintains normal metabolic function, muscle and bone strength, genitourinary health, mood and cognitive functions [33].

Androgens deficiency can lead to a number of distressing sexual symptoms. An "androgen deficiency syndrome" with loss of libido and sense of well-being is well recognized but these symptoms have many other causes. The occurrence, diagnosis and significance of androgen deficiency in women both clinically and biochemically needs to be further clarified [51].

According to the recent consensus referring to testosterone therapy for women (2019) the only evidencebased indication for the use of testosterone in women is for the treatment of postmenopausal women who have been diagnosed as having HSDD after formal biopsychosocial assessment [52]. Patients should be monitored for their clinical response to treatment and assessed for signs of androgen excess with a serum total T concentration every 6 months, to screen for overuse. If no benefit is experienced by this time, treatment should be ceased. Systemic DHEA is not associated with significant improvement in libido or sexual function in postmenopausal women with normal adrenal function and cannot be recommended for women with HSDD [52].

\section{Disclosure}

The authors report no conflict of interest.

\section{References}

1. Hodgson TK, Braunstein GD. Physiological Effects of Androgens in Women Contemporary Endocrinology: Androgen Excess Disorders in Women: Polycystic Ovary Syndrome and Other Disorders, Second Edition 2010. 
2. Sluijmer AV, Heineman MJ, De Jong FH, et al. Endocrine activity of the postmenopausal ovary: the effects of pituitary down-regulation and oo phorectomy. J Clin Endocrinol Metab 1995; 80: 2163-2167.

3. Adashi EY. The climacteric ovary as a functional gonadotropin-driven androgen-producing gland. Fertil Steril 1994; 62: 20-27.

4. Gershagen S, Doeberl A, Jeppsson S et al. Decreasing serum levels of sex hormone-binding globulin around the menopause and temporary relation to changing levels of ovarian steroids, as demonstrated in a longitudinal study. Fertil Steril 1989; 51: 616-621.

5. Clayton AH, Vignozzi L. Pathophysiology and medical management of hypoactive sexual desire disorder. In: Textbook of Female Sexual Function and Dysfunction - Diagnosis and Treatment; Wiley Blackwell: Oxford, UK, 2018: 59-100.

6. Scavello I, Maseroli E, Di Stasi V, et al. Sexual health in menopause. Medicina 2019; 55: 559

7. Rivera-Woll LM, Papalia M, Davis SR, et al. Androgen insufficiency in women: diagnostic and therapeutic implications. Hum Reprod Update 2004; 10: 421-432.

8. Cameron DR, Braunstein GD. Androgen replacement therapy in women Fertil Steril 2004; 82: 273-289.

9. Labrie F, Luu-The V, Labrie C, et al. Endocrine and intracrine sources of androgens in women: inhibition of breast cancer and other roles of androgens and their precursor dehydroepiandrosterone. Endocr Rev 2003; 24: 152-182.

10. Portman DJ, Gass ML. Vulvovaginal Atrophy Terminology Consensus Conference Panel. Genitourinary syndrome of menopause: new terminology for vulvovaginal atrophy from the International Society for the Study of Women's Sexual Health and the North American Menopause Society. J Sex Med 2014; 11: 2865-2872.

11. Tan O, Bradshaw K, Carr BR. Management of vulvovaginal atrophy-related sexual dysfunction in postmenopausal women: an up-to-date review. Menopause 2012; 19: 109-117

12. Nappi RE, Palacios S. Impact of vulvovaginal atrophy on sexual health and quality of life at postmenopause. Climacteric 2014; 17: 3-9.

13. MacBride MB, Rhodes DJ, Shuster LT. Vulvovaginal atrophy. Mayo Clin Proc 2010; 85: 87-94

14. Traish AM, Botchevar E, Kim NN. Biochemical factors modulating female genital sexual arousal physiology. J Sex Med 2010; 7: 2925-2946.

15. Traish AM, Vignozzi L, Simon JA, et al. Role of androgens in female gen itourinary tissue structure and function: Implications in the genitourinary syndrome of menopause Sex Med Rev 2018; 6: 558e571.

16. Simpson ER. Aromatization of androgens in women: current concepts and findings. Fertil Steril 2002; 77 (Suppl 4): S6-S10.

17. Labrie F, Martel C, Bélanger A, et al. Androgens in women are essentially made from DHEA in each peripheral tissue ac- cording to intracrinology. I Steroid Biochem Mol Biol 2017; 168: 9-18.

18. Averette HE, Weinstein GD, Frost P. Autoradiographic analysis of cell pro liferation kinetics in human genital tissues. Normal cervix and vagina. Am J Obstet Gynecol 1970; 108: 8-17.

19. Zumoff B, Strain GW, Miller LK, Rosner W. Twenty-four-hour mean plasma testosterone concentration declines with age in normal premenopausal women. J Clin Endocrinol Metab 1995; 80: 1429-1430.

20. Labrie F, Belanger A, Cusan L, et al. Marked decline in serum concentrations of adrenal C19 sex steroid precursors and conjugated androgen metabolites during aging. J Clin Endocrinol Metab 1997; 82: 2396-2402.

21. Lasley BL, Santoro N, Randolf JF, et al. The relationship of circulating dehydroepiandrosterone, testosterone, and estradiol to stages of the menopausal transition and ethnicity. J Clin Endocrinol Metab 2002; 87: 3760-3767.

22. Fogle RH, Stanczyk FZ, Zhang $X$ et al. Ovarian androgen production in postmenopausal women. J Clin Endocrinol Metab 2007; 92: 3040-3043.

23. Markopoulos MC, Kassi E, Alexandraki KI. Hyperandrogenism after menopause Eur J Endocrin 2015; 172: R79-R91

24. Barbieri RL, Smith S, Ryan KJ. The role of hyperinsulinemia in the pathogenesis of ovarian hyperandrogenism. Fertil Steril 1988; 50: 197-212.

25. Rothman MS, Wierman ME. How should postmenopausal androgen excess be evaluated? Clin Endocrin 2011; 75: 160-164.

26. Alpanes M, Gonzalez-Casbas JM, Sanchez J, et al. Management of postmenopausal virilization. J Clin Endocrinol Metab 2012; 97: 2584-2588.

27. Bachmann G, Cheng RJ, Rovner E. Vulvovaginal complaints. In: Lobo RA, ed. Treatment of the postmenopausal woman: basic and clinical aspects. $3^{\text {rd }}$ ed. Academic Press, Cambridge 2007: 263-269.
28. Simuniæ V. Local estrogen treatment in patients with urogenital symptoms. Int J Gynaecol Obstet 2003; 82: 187-197.

29. Leiblum S, Bachmann G, Kemmann E, et al. Vaginal atrophy in the postmenopausal woman. The importance of sexual activity and hormones. JAMA 1983; 249: 2195-2198

30. Witherby S, Johnson J, Demers L, et al. Topical testosterone for breas cancer patients with vaginal atrophy related to aromatase inhibitors: a phase I/II study. Oncologist 2011; 16: 424-431.

31. Damsted Petersen C. Female sexual function in midlife in Kirana. The EFS and ESSM Syllabus of Clinical Sexology, $1^{\text {st }}$ ed. Medix Publishers, Amsterdam, The Netherlands 2013: 1173-1197.

32. Wierman ME, Arlt W, Basson R, et al. Androgen therapy in women: A reappraisal: An endocrine society clinical practice guideline. J Clin Endocrinol Metab 2014; 99: 3489-3510.

33. Davey DA. Androgens in women before and after the menopause and post bilateral oophorectomy: clinical effects and indications for testosterone therapy. Womens Health 2012; 8: 437-446.

34. Graziottin A, Leiblum SR. Biological and psychosocial pathophysiology of female sexual dysfunction during the menopausal transition. J Sex Med 2005; 2: 133-145.

35. Kadioglu P, Yalin AS, Tiryakioglu O, et al. Sexual dysfunction in women with hyperprolactinemia: a pilot study report. J Urol 2005; 174: 1921-1925.

36. Atis G, Dalkilinc A, Altuntas Y, et al. Sexual dysfunction in women with clinical hypo- thyroidism and subclinical hypothyroidism. J Sex Med 2010; 7: 2583-2590.

37. Veronelli A, Mauri C, Zecchini B, et al. Sexual dysfunction is frequent in premenopausal women with diabetes, obesity, and hypothyroidism, and correlates with markers of increased cardiovascular risk: a preliminary report. J Sex Med 2009; 6: 1561-1568.

38. Pasquali D, Maiorino MI, Renzullo A, et al. Female sexual dysfunction in women with thyroid disorders. J Endocrinol Invest. 2013; 36: 729-733.

39. Krysiak R, Drosdzol-Cop A, Skrzypulec-Plinta V, et al. Sexual function and depressive symptoms in young women with thyroid autoimmunity and subclinical hypothyroidism. Clin Endocrinol (Oxf) 2016; 84: 925-931.

40. Zeleke BM, Bell RJ, Billah B, et al. Hypoactive sexual desire dysfunction in community-dwelling older women. Menopause 2017; 24: 391-399.

41. Atlantis E, Sullivan T. Bidirectional association between depression and sexual dysfunction: a systematic review and meta-analysis. J Sex Med 2012; 9: 1497-1507.

42. Clayton AH. Female sexual dysfunction related to depression and antidepressant medications. Curr Womens Health Rep 2002; 2: 182-187.

43. Stimmel GL, Gutierrez MA. Sexual dysfunction and psychotropic medications. CNS Spectr 2006; 11 (Suppl 9): 24-30.

44. Serretti A, Chiesa A. Treatment-emergent sexual dysfunction related to antidepressants: a meta-analysis. J Clin Psychopharmacol 2009; 29: 259-266.

45. Clayton AH, El Haddad S, lluonakhamhe JP, et al. Sexual dysfunction associated with major depressive disorder and antidepressant treatment. Expert Opin Drug Saf 2014; 13: 1361-1374.

46. Krysiak R, Drosdzol-Cop A, Skrzypulec-Plinta V, et al. Sexual functioning and depressive symptoms in women with diabetes and prediabetes receiving metformin therapy: a pilot study. Exp Clin Endocrinol Diabetes 2017; 125: 42-48.

47. Bajos N, Wellings K, Laborde C, et al. CSF Group. Sexuality and obesity, a gender perspective: results from French national random probability survey of sexual behaviours. BMJ 2010; 340: c2573.

48. Smith AM, Patrick K, Heywood W, et al. Body mass index, sexual difficulties and sexual satisfaction among people in regular heterosexual relationships: a population-based study. Intern Med J 2012; 42: 641-651.

49. Nackers LM, Appelhans BM, Segawa E, et al. Associations between body mass index and sexual functioning in midlife women: the Study of Women's Health Across the Nation. Menopause 2015; 22: 1175-1181.

50. Maseroli E, Fanni E, Cipriani S, et al. Cardiometabolic risk and female sexuality: focus on clitoral vascular resistance. J Sex Med 2016; 13: 1651-1661.

51. Clayton AH, Goldstein I, Kim NN, et al. The International Society for the Study of Women's Sexual Health Process of Care for Management of Hypoactive Sexual Desire Disorder in Women. Mayo Clin Proc 2018; 93: 467-487.

52. Davis SR, Baber R, Panay N, et al. Global Consensus Position Statement on the Use of Testosterone Therapy for Women. J Clin Endocrinol Metab 2019; 104: 4660-4666 